\title{
KERAGAAN FREE SURFACE MODEL PALKA BERBENTUK KOTAK DAN SILINDER
}

\author{
Free Surface Performance of Box and Cylinder Holds Shapes
}

\author{
Oleh: \\ Yopi Novita ${ }^{*}$, Budhi H. Hascaryo ${ }^{1}$, Bambang Murdiyanto ${ }^{1}$, Budy Wiryawan ${ }^{1}$ dan \\ Hariyanto ${ }^{2}$ \\ ${ }^{1}$ Departmenen Pemanfaatan Sumber Daya Perikanan, FPIK, IPB, Jl. Lingkar Kampus, Darmaga - Bogor 16680 \\ 2 Badan Pengkajian dan Penerapan Teknologi, JL. MH.Thamrin No. 8, Jakarta Pusat 10340 \\ ${ }^{*}$ Korespondensi: yop_novita@yahoo.com
}

Diterima: 13 Oktober 2009; Disetujui: 17 Maret 2010

\begin{abstract}
Liquid cargo in the hold of life fish carier might influence ship stability. This is due to effect of free surface that is generated by liquid cargo movement during ship motion. This research examined the effect of free surface from two kinds of hold that are formed into box and cylinder shapes. The result shows that, the effect of free surface of liquid cargo that placed in box shape hold givesless impact comparing to the one in cylinder shape.
\end{abstract}

Key words: box hold, cylinder hold and free surface

\section{ABSTRAK}

Muatan cair yang berada pada palka kapal pengangkut ikan hidup memiliki peluang untuk mempengaruhi stabilitas kapal, karena efek free surface yang ditimbulkan oleh muatan cair tersebut pada saat kapal melakukan gerakan. Penelitian ini bertujuan untuk mengetahui efek free surface dari dua buah bentuk palka yaitu palka kotak dan silinder. Berdasarkan hasil penelitian, efek free surface pada muatan cair yang ditempatkan pada model palka berbentuk kotak memiliki dampak yang lebih kecil dibandingkan pada model palka berbentuk silinder.

Kata kunci: palka kotak, palka silinder dan free surface

\section{PENDAHULUAN}

\section{Latar Belakang}

Transportasi benih ikan kerapu bebek (Cromileptes altivelis) terutama yang berukuran panjang kurang dari $10 \mathrm{~cm}$, saat ini umumnya dilakukan dengan cara memasukkan benih ke dalam kantong plastik yang telah diisi air laut dan oksigen yang dimampatkan dengan komposisi tertentu. Cara ini disebut dengan sistem tertutup. Slamet dkk (2002) dalam penelitiannya menunjukkan bahwa transportasi benih ikan kerapu bebek ukuran panjang kurang dari $10 \mathrm{~cm}$ dengan sistem tertutup yang diberi es batu di luar kantong ikan, rata-rata mampu bertahan hingga 12 jam dalam perjalanan.
Tingkat ketahanan hidup ikan dengan sistem ini berkisar antara 92-99\%. Tingkat ketahanan hidup ikan menurun hingga menjadi $90-97 \%$ jika waktu perjalanan diperpanjang hingga 22 jam. Pada penelitian yang sama, untuk transportasi sistem terbuka, yaitu benih ikan kerapu dimasukkan ke dalam bak yang diisi air laut yang diberi oksigen murni, benih tersebut mampu bertahan hingga 15 jam dengan tingkat ketahanan hidup ikan mencapai $100 \%$. Akan tetapi ditengah perjalanan harus dilakukan penggantian air laut 70-80\% setiap 6-8 jam.

Tulisan ini merupakan bagian dari penelitian utama yang mengkaji tentang resiko kapal pengangkut benih ikan kerapu bebek (Cromileptes altivelis) yang menerapkan sistem peme- 
liharaan kombinasi aerasi dan resirkulasi. Ide perancangan sistem ini diilhami dari sistem pemeliharaan benih ikan kerapu di darat dengan menggunakan bak penampungan yang dilengkapi dengan sistem kombinasi aerasi dan resirkulasi. Diharapkan jika tidak terdapat perbedaan penanganan selama proses transportasi benih dengan penanganan yang dilakukan di balai pembenihan ikan, maka benih ikan tersebut mampu bertahan hidup untuk waktu yang lebih lama. Penerapan sistem resirkulasi pada kapal pengangkut benih ikan kerapu yang direncanakan tersebut, mengakibatkan muatan kapal terbesar adalah berupa muatan berbentuk cair, yaitu air laut dan ikan yang berenang bebas di dalamnya.

Muatan cair mudah berubah bentuk, oleh karena itu Hind (1982) menyarankan pada tangki atau palka yang berisi muatan cairan agar menghindari adanya ruang bebas antara permukaan cairan dengan tutup atau dinding di atasnya (face surface). Kondisi ini dimaksudkan agar stabilitas kapal tidak terganggu akibat adanya efek free surface muatan cair yang berada di dalam tangki atau palka. Akan tetapi pada kapal pengangkut ikan hidup yang direncanakan tersebut, palka tempat menyimpan air laut dan benih ikan, dirancang tidak tertutup secara penuh di bagian atasnya dan bahkan terdapat ruang kosong (face surface) antara permukaan air laut di dalam palka dengan batas atas palka. Hal ini dimaksudkan agar selama perjalanan tetap terjadi interaksi antara permukaan air laut di dalam palka dengan udara diatasnya. Interaksi ini diharapkan memperkaya konsentrasi oksigen air laut yang terdapat di dalam palka. Kondisi ini memberi peluang terjadinya efek free surface yang besar terhadap kapal. Free surface adalah kondisi permukaan yang biasanya terdapat pada benda berbentuk cair. Keberadaan permukaan bebas mengakibatkan benda cair tersebut mudah berubah bentuk sesuai dengan media yang ditempatinya. Efek free surface akan dirasakan terutama saat kapal melakukan gerakan rolling. Saat kapal melakukan gerakan rolling, maka terjadilah pergerakan air dibagian permukaan yang mengikuti arah kemiringan kapal akibat momen yang terjadi. Jika massa air yang bergerak ke sisi kapal yang sedang oleng berlebihan, maka titik berat kapal akan bergeser ke arah kemiringan kapal. Apabila periode oleng kapal sangat lambat, maka kemungkinan kapal akan terbalik menjadi lebih besar. Penelitian tentang efek free surface pada kapal pengangkut ikan hidup telah dilakukan oleh Lee dkk (2005). Braathen and Faltinsen (2002), Naito and Sueyoshi (2002), Shiotani and Kodama (1998), dan Shibata dkk (2007) mencoba mengkaji tentang free surface secara numerik.
Hasil penelitian tersebut diketahui bahwa ketinggian muatan cair dalam tangki, sudut oleng dan periode rolling kapal sangat mempengaruhi besar kecilnya efek free surface yang terjadi. Tulisan ini mengkaji efek free surface dari keberadaan muatan cair di dalam palka kapal pengangkut benih ikan untuk mengurangi resiko terbaliknya kapal.

Kajian efek free surface pada penelitian ini dilakukan dengan membandingkan efek free surface pada bentuk palka yang berbeda, yaitu bentuk kotak dan silinder. Kedua bentuk ini adalah bentuk bak penampung yang umum digunakan di tempat budidaya pembenihan atau pembesaran ikan kerapu bebek.

\section{Tujuan Penelitian}

Penelitian ini bertujuan untuk membandingkan efek free surface yang terjadi pada muatan cair pada model palka berbentuk kotak dan silinder ditinjau dari profil permukaan air saat terjadi dan setelah gerakan rolling kapal serta waktu redam permukaan air saat bergerak hingga kembali tenang.

\section{METODE PENELITIAN}

Penelitian ini dilaksanakan dengan model eksperimen selama bulan Desember 2009, bertempat di Laboratorium Desain dan Dinamika Kapal, Bagian Kapal dan Transportasi Perikanan, Departemen Pemanfaatan Sumber daya Perikanan, FPIK IPB.

\section{Alat dan Bahan}

Alat yang digunakan terdiri dari: 1) Model palka berbentuk kotak, dengan ukuran $\mathrm{p} \times \mathrm{I} \times \mathrm{t}$ $=(25 \times 25 \times 25) \mathrm{cm}^{3}$ (Gambar 1); 2) Model palka berbentuk silinder, dengan ukuran $\varnothing 25$ $\mathrm{cm}$, tinggi $30 \mathrm{~cm}$ (Gambar 2); 3) Jungkat-jungkit untuk memberikan dampak gerakan rolling kapal (Gambar 3); 4) Video camera; 5) Stopwatch

Bahan yang digunakan adalah: air laut dan pewarna merah.

\section{Jenis dan Metode Pengumpulan Data}

Jenis data yang dikumpulkan terdiri dari: 1) Profil permukaan air saat terjadi rolling; 2) Profil permukaan air selama $\pm 1,0$ detik mulai saat kapal kembali tegak setelah terjadi gerakan rolling; 3) Waktu redam, yaitu waktu yang dibutuhkan oleh permukaan air untuk kembali tenang yang dihitung mulai saat palka kembali tegak setelah terjadi gerakan rolling.

Pengumpulan data dilakukan dengan cara eksperimen, dimana ke dalam kedua palka dimasukkan air laut yang telah diberi warna 
merah dengan volume air laut yang sama, yaitu

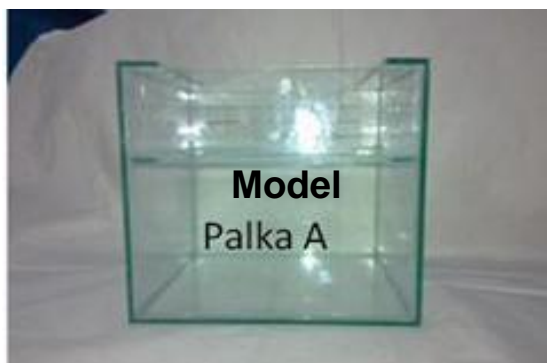

Gambar 1 Model palka bentuk kotak

(Palka A).

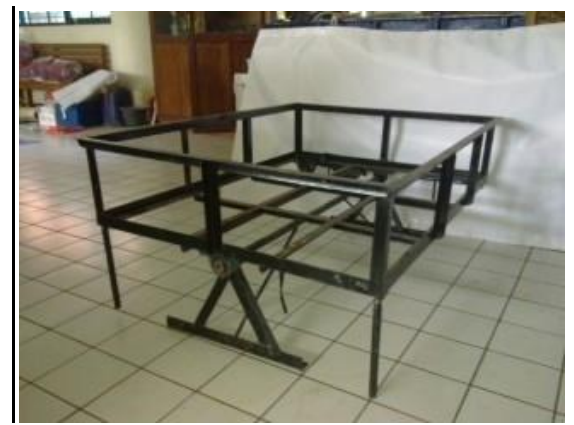

(a) Tampak samping-depan
9,04 liter. Maksud pemberian warna pada air

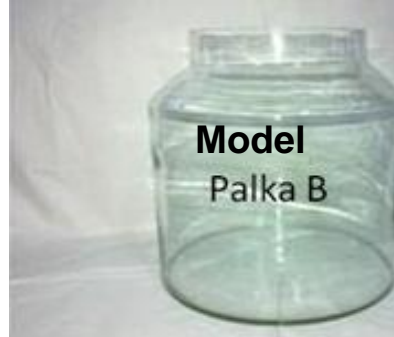

Gambar 2 Model Palka bentuk silinder (Palka B).

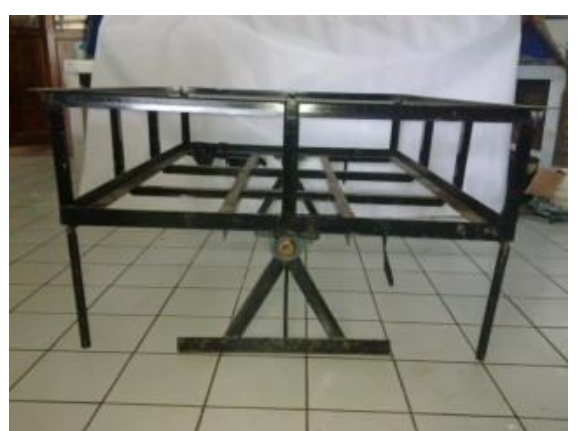

(b) Tampak depan

Gambar 3 Piranti jungkat-jungkit.

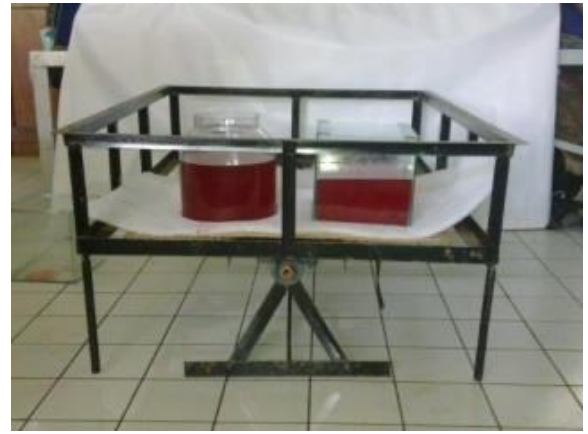

(a) Tampak depan

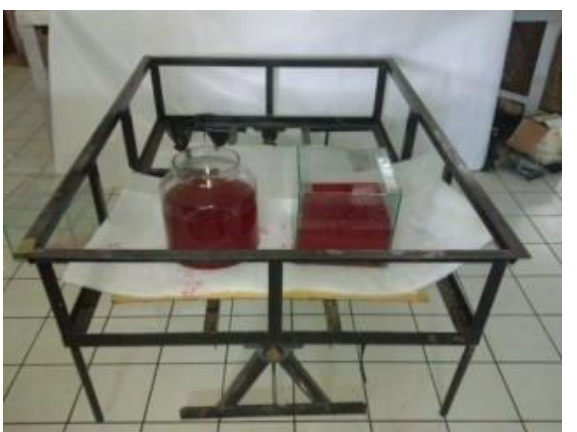

(b) Tampak depan-atas

Gambar 4 Peletakkan kedua palka di atas piranti jungkat-jungkit saat eksperimen.
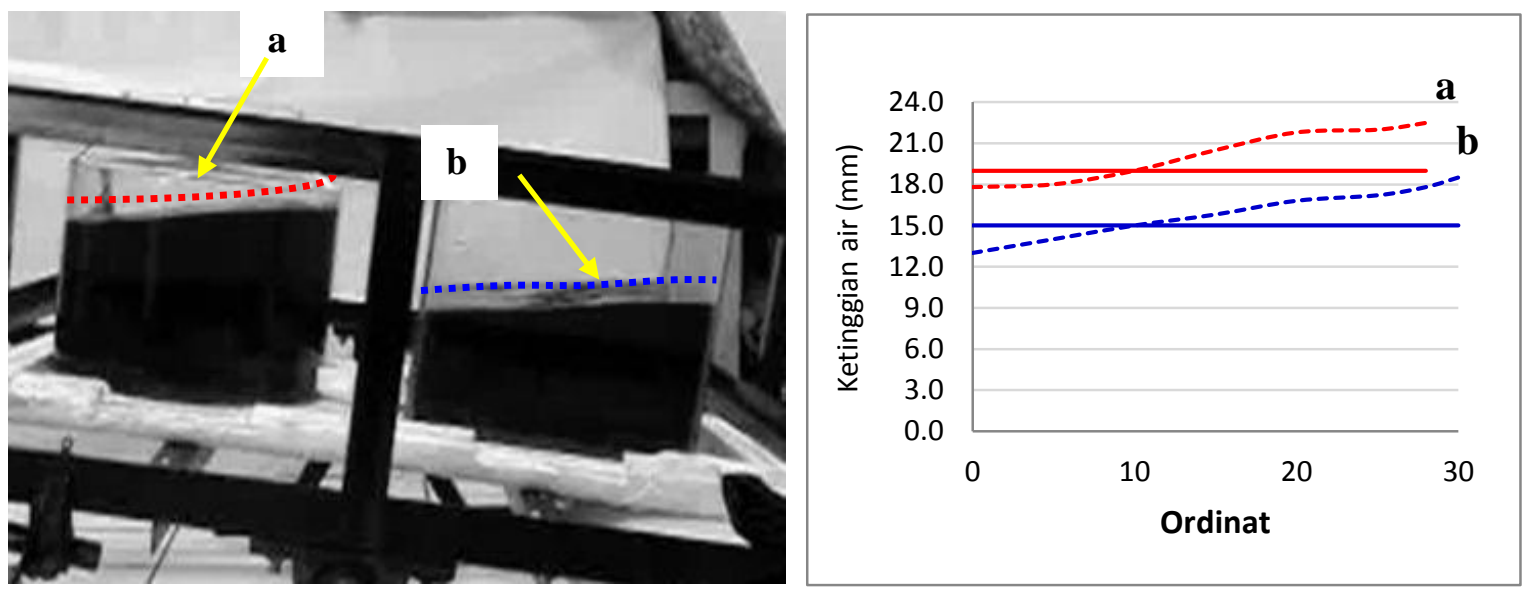

Keterangan: $\quad \mathrm{a}=$ garis air pada model palka kotak $\mathrm{b}=$ garis air pada model palka silinder 
Gambar 5 llustrasi pembuatan grafik garis air.

yang dimasukkan ke dalam model palka adalah agar lebih jelas profil permukaan air saat model palka digerakkan. Saat kedua palka diisi air laut dengan volume yang sama baik pada palka $A$ dan B masing-masing permukaan memiliki jarak dengan bagian atas palka sebesar $10 \mathrm{~cm}$. Selanjutnya kedua palka tersebut diletakkan di atas jungkat-jungkit yang nantinya dimiringkan ke kanan dan ke kiri selayaknya gerakan rolling yang terjadi pada kapal (Gambar 4). Kemiringan jungkat-jungkit sekitar $10^{\circ}$ ke kiri dan kanan dengan periode rolling 2 detik. Ulangan dilakukan sebanyak tiga kali.

\section{Pengolahan dan Analisis Data}

Pengolahan data dilakukan secara numerik, dengan terlebih dahulu merubah garis air yang terdapat pada dinding model palka dalam format foto menjadi grafik garis air (Gambar 5). Selanjutnya akan dihasilkan profil kemiringan permukaan air dan profil permukaan air setelah terjadi rolling dalam bentuk grafik. Dari grafik dapat diukur sudut kemiringan permukaan air $\left.{ }^{\circ}{ }^{\circ}\right)$ dan ketinggian riak yang timbul di permukaan air (mm).

Analisis data dilakukan secara komparatif. Perbandingan dilakukan antara profil kemiringan permukaan air dan profil permukaan air setelah terjadi rolling pada model palka kotak dengan model palka silinder.

\section{HASIL DAN PEMBAHASAN}

Efek free surface dalam penelitian ini ditinjau dari profil permukaan air pada saat terjadi gerakan oleng dalam hal ini adalah implementasi dari dampak gerakan rolling kapal (diistilahkan sebagai "profil kemiringan") dan profil permukaan air saat tidak ada lagi gerakan rolling hingga permukaan air relatif tenang (diistilahkan sebagai "profil diam"). Selain itu kajian juga dilakukan terhadap lamanya waktu yang dibutuhkan oleh permukaan air mulai dari saat gerakan rolling berhenti hingga permukaan air relatif tenang atau stabil yang untuk selanjutnya diistilahkan sebagai "waktu redam".

\section{Profil Kemiringan Permukaan Air}

Profil kemiringan diperoleh dengan menggerakkan jungkat-jungkit ke atas dan ke bawah hingga mencapai sudut sekitar 10․ Diperkirakan panjang lintasan gerakan rolling dari kemiringan di sisi kiri ke kemiringan di sisi kanan kapal dan kembali ke kemiringan di sisi kiri kapal sekitar $40^{\circ}$ atau 0,698 radian. Pengamatan terhadap kemiringan permukaan air dilakukan saat palka mencapai kemiringan maksi- mal yaitu $10^{\circ}$ ke kiri dan ke kanan. Contoh profil kemiringan permukaan air yang terjadi disampaikan pada Gambar 6. Gambar tersebut memperlihatkan adanya perbedaan ketinggian permukaan air. Kondisi ini terjadi karena perbedaan bentuk palka dengan volume air yang sama dimasing-masing palka tersebut menyebabkan ketinggian air yang dihasilkan berbeda. Model palka silinder (Palka B) memiliki ketinggian permukaan air yang lebih tinggi dibandingkan dengan ketinggian permukaan air di model palka kotak (palka A).

Gambar tersebut memperlihatkan bahwa profil kemiringan permukaan air pada model palka kotak dan model palka silinder memiliki profil yang relatif sama. Hal ini dibuktikan dengan hasil pengukuran sudut kemiringan permukaan air terhadap garis yang sejajar permukaan air saat sebelum terjadinya gerakan rolling (Tabel 1). Tabel tersebut memperlihatkan tidak adanya perbedaan sudut kemiringan permukaan air baik pada model palka $A$ dan palka B.

Shibata et al. (2007) telah mengkaji hubungan gerakan kapal dengan "green water" di atas dek kapal. "Green water" adalah istilah untuk keberadaan air di atas dek kapal. Penelitian tersebut mengungkapkan bahwa bentuk permukaan bebas (free surface), tidak mempengaruhi efek yang akan ditimbulkannya. Informasi inilah yang menjelaskan mengapa profil kemiringan permukaan air pada model palka $A$ dan model palka $B$ saat terjadi rolling tidak menunjukkan perbedaan. Akan tetapi jika diperhatikan bentuk ujung permukaan air yang tertahan oleh dinding palka, terdapat perbedaan, yaitu bentuk ujung permukaan air pada model palka A lebih landai dibandingkan pada model Palka B. Penelitian Bai (2005) terhadap aliran free surface pada ketinggian permukaan air yang berbeda, menjawab fenomena tersebut.

Hasil penelitian tersebut mengungkapkan bahwa permukaan air yang lebih rendah akan memiliki bentuk aliran free surface yang landai pada saat bertubrukan dengan dinding pembatas. Adapun pada permukaan air yang lebih tinggi bentuk aliran free surface saat bertubrukan dengan dinding pembatas berbentuk curam. Bentuk aliran free surface yang landai pada ujung yang bertubrukan dengan dinding pembatas akan menghasilkan gelombang balik yang lebih sedikit dan landai dibandingkan dengan bentuk aliran free surface yang curam. Kondisi ini mengakibatkan permukaan air yang lebih rendah akan lebih cepat stabil atau tenang kembali setelah tidak ada gaya eksternal yang mengganggunya. 
Lee et al. (2005) dalam penelitiannya mengkaji keragaan gerakan rolling kapal ikan

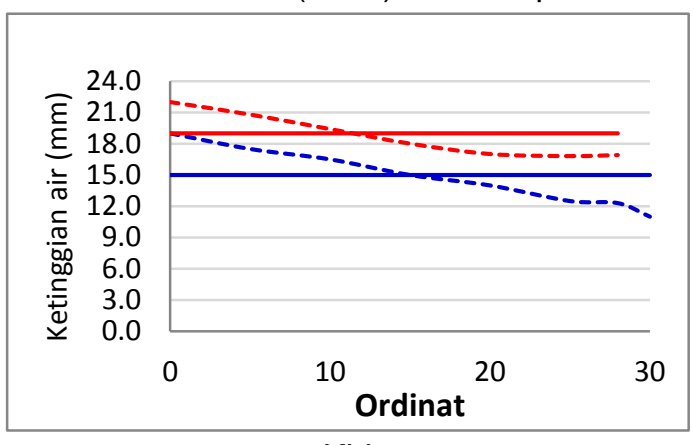

Kiri

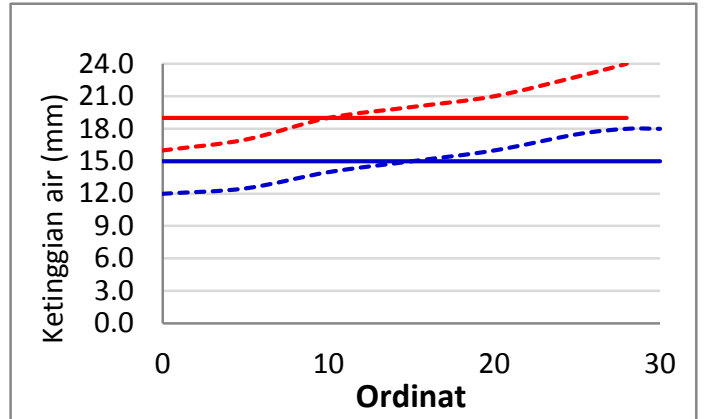

Kanan

Keterangan:

---Palka B ---Palka A Rata air Palka B Rata air Palka A

Gambar 6 Profil permukaan air saat rolling.

Tabel 1 Sudut kemiringan permukaan air saat rolling

\begin{tabular}{|c|c|c|c|}
\hline \multirow{2}{*}{ Posisi } & \multicolumn{2}{|c|}{ Kemiringan air $(\stackrel{\circ}{*})$} & \multirow{2}{*}{$\begin{array}{c}\text { Beda kemiringan } \\
(\stackrel{0}{\text { Bon }})\end{array}$} \\
\hline & Model palka kotak & Model palka silinder & \\
\hline Kiri 1 & 7 & 7 & 0 \\
\hline Kanan 1 & 5 & 5 & 0 \\
\hline Kiri 2 & 8 & 8 & 0 \\
\hline Kanan 2 & 8 & 9 & -1 \\
\hline Kiri 3 & 9 & 9 & 0 \\
\hline Kanan 3 & 6 & 7 & -1 \\
\hline
\end{tabular}

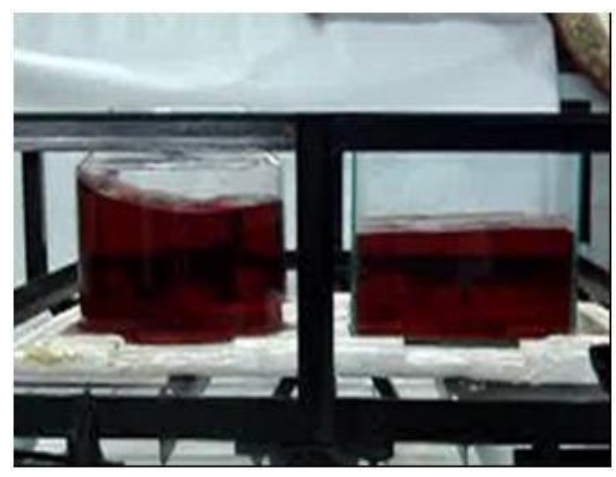

Keterangan:

-.---Palka B

Palka A

Rata air Palka B

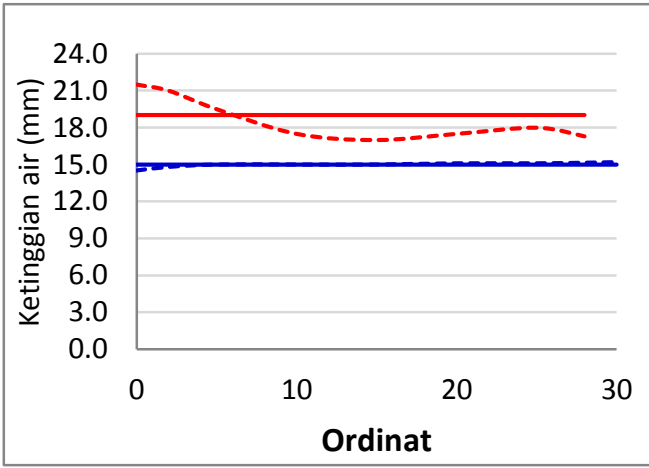

Gambar 7 Profil permukaan air saat palka kembali tegak setelah rolling (0 detik). 

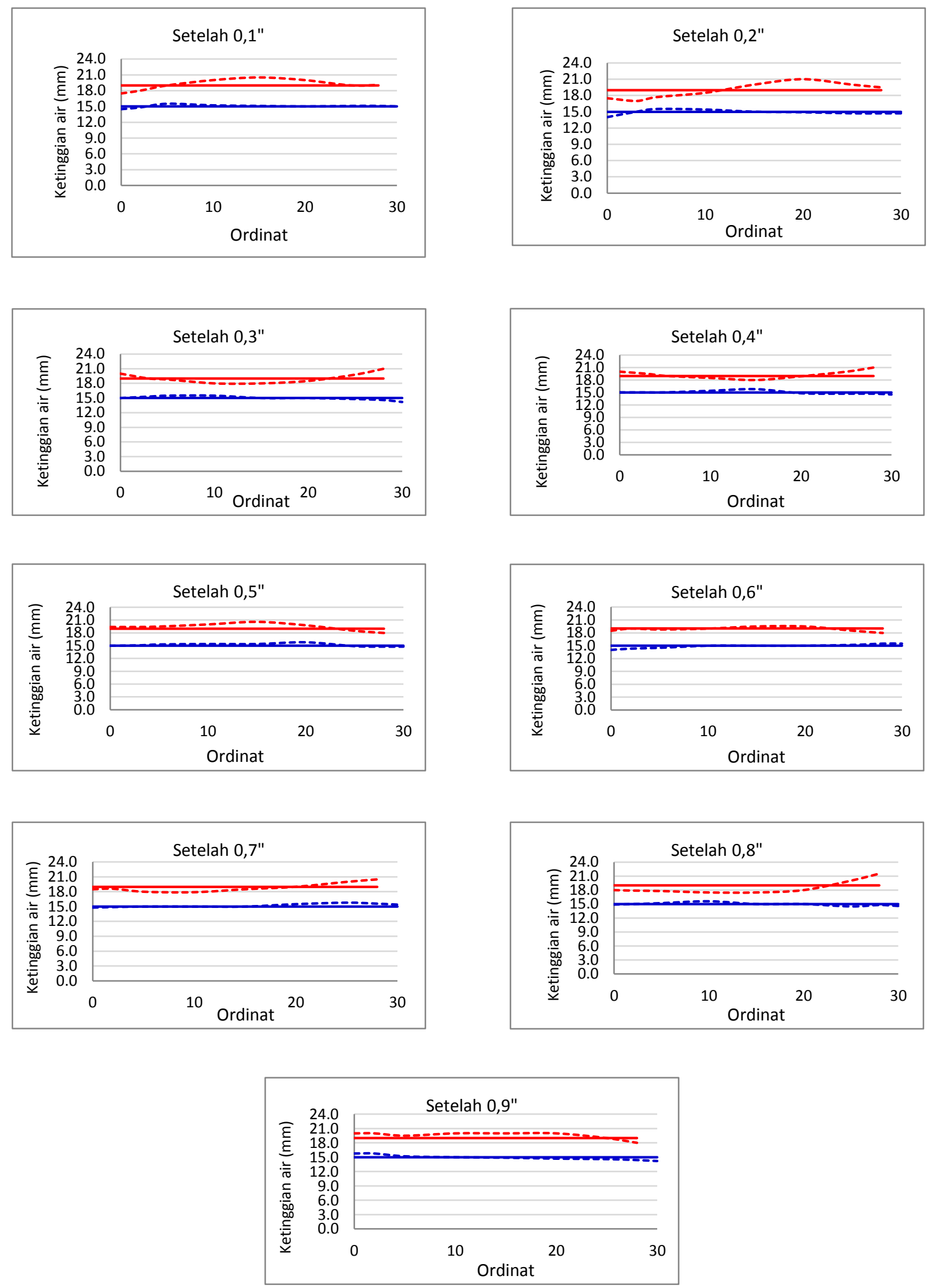

Keterangan:

-.--- Palka B

Palka A Rata air Palka B

Rata air Palka A

Gambar 8 Profil permukaan air setelah 0,1-0,9 detik setelah palka kembali tegak. 


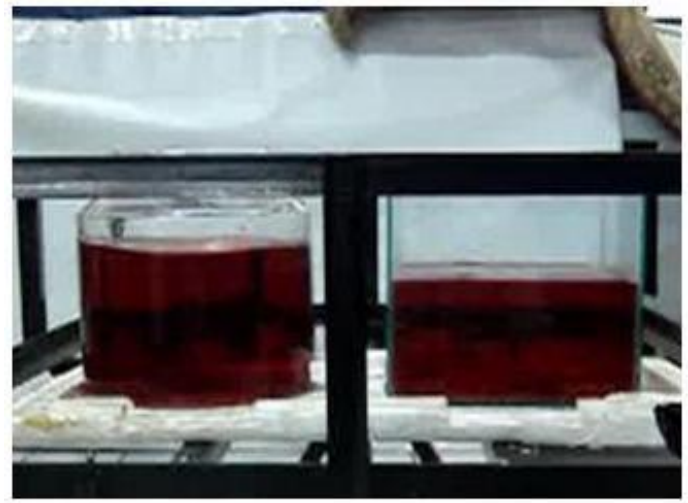

Keterangan:

-.-- Palka B

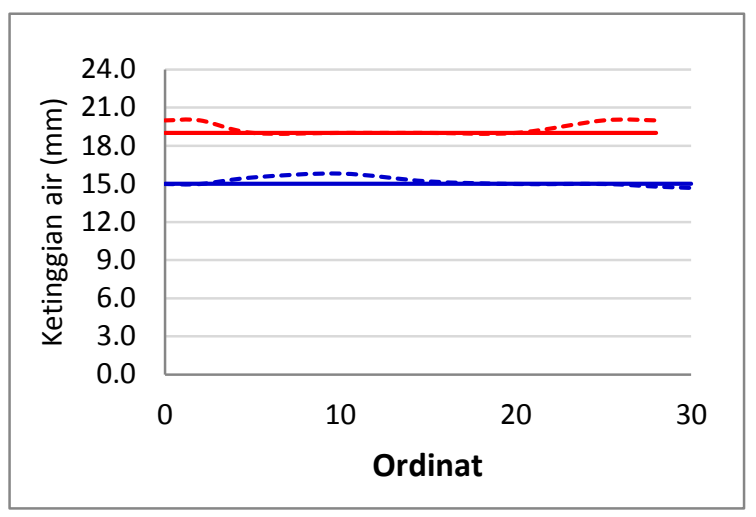

Rata air Palka B
Rata air Palka A

Gambar 9 Profil permukaan air setelah 1 detik palka kembali tegak.

yang dilengkapi dengan palka ikan hidup, mengemukakan bahwa keberadaan free surface akan meningkatkan damping moment coefficient kapal. Semakin tinggi keberadaan free surface tersebut, akan meningkatkan damping moment coefficient kapal. Jika damping moment meningkat maka kemampuan kapal untuk meredam gaya eksternal yang mengenai kapal (gelombang), akan semakin berkurang.

Berdasarkan kajian sebelumnya diperkirakan bahwa efek free surface akan lebih besar dirasakan oleh kapal yang menggunakan palka berbentuk silinder. Jika dihubungkan dengan damping moment coefficient kapal, maka diperkirakan damping moment coefficient pada kapal dengan palka silinder akan lebih besar bila dibandingkan dengan kapal yang memakai palka kotak. Kemampuan kapal dengan palka silin-der untuk meredam gaya eksternal akan lebih kecil dibandingkan dengan kapal yang memakai palka kotak. Mengecilnya kemampuan redam kapal akan mengakibatkan stabilitas kapal menurun karena dinamika kapal lebih banyak dipengaruhi oleh gaya eksternal.

Akan lain permasalahannya jika pada kedua palka diisi penuh oleh air laut, apabila terjadi gerakan rolling, maka tidak akan terjadi pergerakan fluida dipermukaannya. Sehingga tidak akan terjadi perubahan posisi titik berat di palka yang pada akhirnya tidak akan mempengaruhi stabilitas kapal. Pengkondisian ini mengakibatkan volume air laut di dalam model palka $A$ lebih besar dibandingkan dengan model palka B.

\section{Profil Permukaan Air Setelah Terjadi Rolling}

Setelah model palka A dan B diolengkan ke kanan dan ke kiri selama kurang lebih 20 detik, selanjutnya model palka A dan B diposisikan tegak kembali. Pengamatan mulai dilaku- kan terhadap profil permukaan air mulai saat posisi model palka tegak hingga 1 detik kemudian. Profil permukaan sesaat setelah posisi model palka ditegakkan dapat dilihat pada Gambar 7.

Sebagaimana hasil penelitian Bai (2005), pada gambar (7), permukaan air pada model palka $B$ yang lebih tinggi dibandingkan di model palka A nampak sangat dinamis dibandingkan dengan permukaan air pada model palka $A$ yang nampak seakan-akan langsung stabil. Selanjutnya dilakukan pengamatan terhadap bentuk permukaan air serta ketinggian permukaan air pada profil permukaan air setiap 0,1 detik selama 1 detik (Gambar 8). Gambar 8 memperlihatkan pada ordinat pengukuran tertentu, menjelang 1 detik pengamatan, permukaan air model palka A semakin banyak yang telah menyamai garis rata air pada saat tidak ada gerakan. Berdasarkan ketinggian permukaan air pada ordinat pengukuran, terlihat bahwa ketinggian permukaan air pada ordinat-ordinat pengukuran pada model palka A cenderung lebih rendah dibandingkan pada model palka $B$.

Permukaan air yang lebih tinggi pada model palka $B$ menunjukkan bahwa permukaan air pa-da model palka $B$ lebih dinamis dibandingkan pada model palka A. Apabila permukaan muatan cair di dalam palka sangat dinamis, maka kondisi kapal untuk kembali tegak setelah gaya yang mengakibatkan gerakan rolling kapal hilang akan lebih sulit. Perlu diketahui bahwa walaupun palka sudah tidak diolengkan, akan tetapi gerakan fluida cair masih terus terjadi terlebih jika fluida cair tersebut terus bertubrukan dengan dinding pembatas.

Pada Gambar 9 disajikan profil permukaan air pada kedua model palka setelah 1 detik. Terlihat bahwa pada model palka A permukaan airnya relatif telah lebih banyak bagian yang 
telah sejajar dengan garis rata air dibandingkan dengan pada model palka $\mathrm{B}$.

\section{Waktu Redam}

Waktu redam adalah lamanya waktu yang dibutuhkan oleh permukaan air di dalam model palka, mulai dari saat gerakan rolling berhenti hingga permukaan air tersebut relatif tenang kembali atau stabil. Dari tiga kali ulangan, terlihat bahwa waktu redam permukaan air pada model palka $A$ adalah antara 9-13 detik. Adapun di model palka $B$ waktu redam per-mukaan air adalah antara 27-37 detik. Waktu redam permukaan air di model palka $A$ lebih kecil dibandingkan di model palka B. Bahkan dari data waktu redam, permukaan air pada model palka A rata-rata tiga kali lebih cepat stabil dibandingkan dengan permukaan air pada model palka $B$.

Waktu redam permukaan air yang lebih singkat pada model palka A dimungkinkan terjadi, mengingat profil ujung aliran permukaan air pada dinding palka yang landai mengakibatkan tekanan balik pada ujung aliran saat bertubrukan dengan dinding palka tidak terlalu besar, sehingga momen tubrukan antara aliran air di permukaan dengan dinding pembatas tidak terlalu besar. Kondisi inilah yang mengakibatkan waktu redam permukaan air pada model palka A lebih cepat dibandingkan dengan di model palka $B$ yang memiliki profil ujung aliran permukaan air pada dinding palka yang curam. Hal ini dibuktikan pula oleh ketinggian permukaan air terhadap garis rata air di model palka A yang cenderung lebih rendah dibandingkan di model palka $B$ selama 1 detik pengamatan.

Bentuk palka silinder yang lebih hidrodinamis dibandingkan dengan palka kotak, memungkinkan gerakan permukaan air di dalam palka silinder lebih dinamis. Hal ini dikarenakan tidak ada bagian di dalam palka silinder yang dapat menghambat gerakan atau aliran muatan cair atau fluida cair tersebut.

\section{KESIMPULAN}

Berdasarkan kajian terhadap profil permukaan air baik pada saat terjadi oleng maupun setelah oleng dan waktu yang dibutuhkan oleh permukaan air untuk kembali tenang setelah terjadi gerakan oleng, maka dapat dipastikan bahwa pada palka berbentuk silinder memiliki efek free surface lebih besar dibandingkan pada palka berbentuk kotak. Dari hasil penelitian ini, untuk mengurangi besarnya efek free surface yang ditimbulkan, disarankan untuk menggunakan palka berbentuk kotak pada saat pengangkutan muatan berbentuk cair (liquid cargo).

\section{DAFTAR PUSTAKA}

Braathen, A. And O.M. Faltinsen. 1988. Interaction Between Shed Vorticity, Free Surface Waves and Forced Roll Motion of a Two-Dimensional Floating Body. Fluid Dynamics Research. Volume 3, Issues 1-4. September 1988. Pages: 190-196.

Hind, J.A. 1982. Stability and Trim of Fishing Vessels. Second edition. Fishing News Books Ltd. Farnham, England. $131 \mathrm{p}$.

Lee, S.K., S. Surendran dan G. Lee. 2005. Roll Performance of Small Fishing Vessel with Live Fish Tank. Ocean Engineering 32 (2005): 1873-1885.

Naito, S. and M. Sueyoshi. 2002. A Numerical Analysis of Violent Free Surface Flow by Particle Method. Proceedings of The Fifth (2002) ISOPE Pacific/Asia Offshore Mechanics Symposium, Daejeon, Korea, November 17-20, 2002.

Sames, P.C., D. Marcouly, and T.E. Schellin. 2002. Sloshing in rectangular and cylindrical tanks. Journal of Ships Research 46 (3), Pages: 186-200.

Shibata, K., K. Tanizawa and S. Koshizuka. 2007. Numerical Analysis of Coupling Between Ship Motion and Green Water on Deck using MPS Method. Proceeding of International Conference on Violent Flows (VF-2007), Fukuoka, Japan.

Shiotani, S. and Y. Kodama. 1998. Numerical Analysis on Free Surface Waves and Stern Viscous Flow of a Ship Model. Journal of Marine Science and Technology. Vol. 3, Pages: 130-144.

Slamet, B., S. Ismi dan T. Aslianti. 2002. Transportasi Benih Ikan Kerapu Bebek (Cromileptes altivelis) Hasil Pembenihan di Bali. Ntb.litbang.deptan.go.id/ 2002/ NP/transportasibenih.doc (1 September 2009). 